\title{
Do diabetes and depressed mood affect associations between obesity and quality of life in postmenopause? Results of the KORA-F3 Augsburg population study
}

\author{
Daniela A Heidelberg ${ }^{1}$, Rolf Holle ${ }^{2}$, Maria E Lacruz ${ }^{3}$, Karl-Heinz Ladwig ${ }^{3}$ and Thomas von Lengerke $e^{1,2^{*}}$
}

\begin{abstract}
Background: To assess associations of obesity with health-related quality of life (HRQL) in postmenopausal women, and whether depressed mood and diabetes moderate these associations.

Methods: Survey of 983 postmenopausal women aged 35-74, general population, Augsburg region/Germany, 2004/2005. Body weight/height and waist/hip circumference were assessed anthropometrically and classified via $\mathrm{BMI} \geq 30$ as obese, and WHR $\geq 0.85$ as abdominally obese (vs. not). Depressed mood was assessed by the Depression and Exhaustion-(DEEX-)scale, diabetes and postmenopausal status by self-report/medication, and HRQL by the SF-12.

Results: General linear models revealed negative associations of obesity and abdominal obesity with physical but not mental HRQL. Both forms of excess weight were associated with diabetes but not depressed mood. Moderation depended on the HRQL-domain in question. In non-diabetic women, depressed mood was found to amplify obesity-associated impairment in physical HRQL (mean "obese"-"non-obese" difference given depressed mood: -6.4, $\mathrm{p}<.001$; among those without depressed mood: $-2.5, \mathrm{p}=.003$ ). Reduced mental HRQL tended to be associated with obesity in diabetic women (mean "obese"-"non-obese" difference: $-4.5, p=.073$ ), independent of depressed mood. No interactions pertained to abdominal obesity.
\end{abstract}

Conclusions: In postmenopausal women, depressed mood may amplify the negative impact of obesity on physical HRQL, while diabetes may be a precondition for some degree of obesity-related impairments in mental HRQL.

Keywords: obesity, health-related quality of life, postmenopause, depressed mood, diabetes mellitus

\section{Background}

While the evidence on the effects of the menopausal transition on health-related quality of life (HRQL) is inconclusive [1], it is rather clear regarding effects of menopausal symptoms [2]. Avis et al. [3] found that the menopausal transition showed little impact on physical HRQL when adjusted for symptoms, medical conditions, and stress. Williams et al. [4] revealed that postmenopausal women with severe vasomotor symptoms felt

\footnotetext{
* Correspondence: lengerke.thomas@mh-hannover.de

'Hannover Medical School, Medical Psychology Unit (OE 5430), Carl-

Neuberg-Str. 1, 30625 Hannover, Germany

Full list of author information is available at the end of the article
}

more impaired in their daily activities than those with moderate or mild symptoms. Timur and Sahin [5] showed that menopause-specific quality of life was impaired in menopausal women with sleep disturbances. Finally, van Dole et al. [6] found that in postmenopausal period, increasing vasomotor symptoms were associated with a small but significant increase in psychosocial symptoms (e.g. dissatisfaction with personal life).

The role of chronic medical conditions for HRQL in postmenopause seems less clear. Avis et al. [3] studied arthritis and migraines, and found that especially the former contributed to reduced physical HRQL. SanfélixGenovés et al. [7] identified osteoporotic vertebral 
fractures to be associated with significantly lowered physical HRQL. Schwarz et al. [8] used a multi-morbidity index including hypertension, unspecified chronic back pain, arthrosis, varicosis, elevated blood lipids, migraine, thyroid disease, osteoporosis, arthritis and diabetes mellitus. Multi-morbidity was linearly associated with pain and gastrointestinal symptoms. However, due to sumscoring no assertions could be drawn as to which diseases produced the differences. In their review, Jones and Sutton [9] argued that a condition particularly important for postmenopausal HRQL is obesity, as women tend to gain weight especially during the menopausal transition.

Although obesity has been shown to be associated with reduced physical HRQL, in most studies no association has been found for mental HRQL [10]. A comparable assertion holds for postmenopausal obesity, which is associated with poor HRQL, particularly regarding physical functioning, energy/vitality, and general health perceptions [9]. This is surprising considering the shared biology of obesity and depression [11]. Also, social stigmatisation associated with obesity may reduce mental HRQL [12]. Therefore, postmenopausal women who are obese could be expected to be more impaired in mental HRQL than their non-obese counterparts. Possibly, the existing small associations may be explained by restrictions of decreased mental HRQL to obese groups with co-morbidities. E.g., Banegas et al. [13] found cumulative effects of obesity, diabetes and hypertension on HRQL in women 60 years or older. Obese women with diabetes showed greater-than-additive declines not only in physical, but mental HRQL as well. Regarding mental morbidity, Ladwig et al. [14] found a small synergistic effect of depressed mood with obesity on long-term cardiovascular risk in obese women aged 45 to 74 years.

Considering these findings and the pathophysiological cluster including visceral fat, depressive and metabolic disorders [15], the present study investigates the synergistic effects of obesity, depressed mood and diabetes mellitus (as examples of chronic conditions) on physical and mental HRQL in postmenopausal women from the general population.

\section{Methods}

\section{Population and sampling}

The present sample of 983 postmenopausal women was derived as follows. To begin with, data come from a general population survey in the Augsburg region, Germany. This survey (F3) was conducted in 2004-2005 within the Cooperative Health Research in the Region of Augsburg (KORA [16]) as a follow-up to a 1994-1995 survey (S3). Central elements of data collection were a computer-aided personal interview (CAPI), a self- administered questionnaire, physical examination by trained personal (including assessments of body weight and height) and blood sampling.

The sample of the original 1994-1995 survey (S3) had been selected from 394,756 German residents aged 2574 in 1994 via two-stage random cluster sampling. First, 17 communities were selected (probabilities proportional to size): Augsburg city and 16 communities from the two adjacent counties. In each community and within each of 10 strata defined by sex and 10-year age groups, a simple random sample was drawn from public registry office listings.

In the follow-up (F3), 3,006 S3-respondents participated (response: 76\%). Additionally, of former nonresponders, $178(14 \%)$ participated, giving a total $\mathrm{N}$ of 3,184 (aged: 35-84). Approval of the responsible Ethics Committee (Bayerische Landesärztekammer, Munich, Germany) and informed consent of all survey participants was secured.

All participants of the follow-up F3 who were older than 74 years were excluded since some measures relevant to the present study had not been administered to them to avoid undue burden $(\mathrm{N}=371)$. Underweight respondents (BMI in $\mathrm{kg} / \mathrm{m}^{2}<18.5, \mathrm{~N}=15$ ) as well as participants living outside the study region $(\mathrm{N}=30)$ were excluded. Finally, 29 had refused and 7 had been too ill or had no time to fill in the questionnaire.

Of the remaining 2,732 F3-participants, all men $(\mathrm{N}=$ $1,312)$, all premenopausal women $(\mathrm{N}=433$, see below) and 4 women with no information on menopausal status were excluded from the present analysis. Thus, eventually a sample of $\mathrm{N}=983$ postmenopausal women was available for analysis.

While a non-responder analysis is not available for the KORA study F3, information on non-responders from the same population and a similar survey design can be extrapolated from a non-responder analysis of the former KORA-study S4 [17]. In this analysis, $49 \%$ of the initial non-responders had participated and - compared with responders - more often had lower education (maximally secondary school with low academic level [German: "Hauptschule"]: 65\% vs. 54\%) and fair or poor self-rated health ( $28 \%$ vs. $21 \%)$, were more often unmarried ( $34 \%$ vs. $29 \%)$ and smokers (29\% vs. $26 \%)$, and more frequently reported physician visits in the last four weeks ( $46 \%$ vs. $38 \%)$, myocardial infarction ( $6 \%$ vs. $3 \%$ ), and diabetes ( $7 \%$ vs. $4 \%)$.

\section{Measures \\ $H R Q L$}

HRQL was assessed via the first edition of German version of the SF-12 (1998, self-administered version) [18], a generic quality of life instrument with good reliability and validity. It yields one continuous summary score 
each for subjective physical and mental health. Scores range from 0 to 100 , with higher values indicating better HRQL.

\section{Postmenopausal status}

Postmenopausal status was assessed via self-report in a computer-aided personal interview (CAPI) based on the items "Have you had menses within the last 12 months?", "Do you still have regular menstruation?", and "At present, are you pregnant?". Corresponding to established definitions [1], "postmenopausal" was coded given amenorrhea in the preceding 12 months and no current regular menses. Women with postmenopausal status due to surgical procedures such as oophorectomy or hysterectomy were also included. Women with systemic hormonal therapy (HT) were not automatically classified as "postmenopausal", but only if they met the indicated conditions. It was not focused on in the analyses, but considered as a confounder. HT has been argued to have the potential to improve HRQL in postmenopausal women. In this sample, current HT users (14\%) reported poorer HRQL (as in [3]), especially in the mental domain. Regarding the effects of obesity, depressed mood and diabetes on HRQL, neither additional adjustment for current nor ever HT altered any of the interaction effects reported below.

\section{Obesity}

Obesity was assessed by anthropometric examinations. Body mass was indexed into BMI by dividing weight $(\mathrm{kg})$ by squared height $\left(\mathrm{m}^{2}\right)$. Due to subsample sizes (diabetes prevalence: $8.3 \%$ ), only two BMI-groups were contrasted (WHO-classification): "non-obese" $(5 \leq \mathrm{BMI}<30)$ and "obese" (BMI $\geq 30)$. Abdominal obesity was defined as waist-to-hip ratio (WHR) of $\geq 0.85$ [19]. WHR was selected since it is approximately equivalent to waist circumference regarding its association with diabetes among women [20]. Also, it is a mediator in the relationship between obesity and depression [21], and (following weight) the second most important anthropometric predictor of female bodily attractiveness [22].

\section{Diabetes mellitus}

Diabetes was assessed via self-report and current antidiabetic medication. Regarding medication, participants were asked to bring drug packages or package inserts of drugs they currently use. Self-reports and medication were compared and, given conflicting data, interviewer notes and audio-recordings checked.

\section{Depressed mood}

Depressed mood was assessed by the Depression and Exhaustion (DEEX) scale [23] based on the von-Zerssen-Symptom-List [24]. The scale combines eight items (fatiguability, tiredness, irritability, inner tension, nervousness, anxiety, loss of energy, and difficulty in concentrating) leading to a Likert-like scale (scores from 0 to 24) normally distributed and with sufficient internal consistency $(\alpha=0.88)$. Subjects in the top tertile of the distribution were considered as index group for subjects with depressed mood [23].

\section{Sociodemographic/-economic variables}

Gender, age and place of residence (rural vs. urban) were known via sampling. Family status and socioeconomic status (SES) were assessed via interview. SES was operationalised by school education, as in Germany it relates stronger to obesity than income or occupational status [25]. Respondents indicated their highest education level: primary or secondary general school ("Grundschule" or "Hauptschule" in Germany), intermediate secondary ("Realschule"), or grammar/upper secondary school ("Gymnasium").

\section{Statistical analysis}

Following descriptive and bivariate analyses, general linear modelling (GLM) was conducted using the PASWStatistics-18 software. For each HRQL summary score, one model was run to test for differences by obesity (or abdominal obesity), depressed mood, and diabetes. Because of previously reported difficulties to detect interactions in field studies [26], significance level for interactions was set at $\mathrm{p}<.1$, vs. $\mathrm{p}<.05$ for main effects (two-tailed). Given a significant interaction, stratified analyses were conducted to clarify the underlying pattern, i.e., with either obesity or abdominal obesity defined as the focal independent variable, simple effects or (given three-way interactions) simple simple effects [27] were tested. For stratified analysis, 95\%-confidence intervals for mean differences were calculated. Outlier trimming was not applied. All models were adjusted for age, education, family status, type of health insurance (statutory vs. private), and place of residence (urban vs. rural).

\section{Results}

\section{Descriptive and bivariate analysis}

Table 1 describes the sample. Overall, 29.5\% of the 983 women were classified as obese, while $43.1 \%$ as having abdominal obesity. Only a small minority was younger than 45 years (4.4\%). Almost two thirds had only low school education. Nearly three-fourths lived with a partner. About one eighth had private health insurance, which is close to the overall German rate (10.5\%). Furthermore, $44.9 \%$ lived in the city of Augsburg, 8.3\% had diabetes, and $40 \%$ met the criteria for depressed mood.

Bivariately, women with both general and abdominal obesity were older than their non-obese counterparts, and more often had completed secondary general school only. Regarding diabetes, its prevalence was about threefold in the obese group, and about fourfold in those 
Table 1 Sample description: bivariate cross-tabulations of demographics, diabetes mellitus and depressed mood with obesity and abdominal obesity

\begin{tabular}{|c|c|c|c|c|c|c|c|c|c|c|c|c|c|c|}
\hline \multirow[b]{2}{*}{ Characteristic } & \multicolumn{2}{|c|}{ Total } & \multicolumn{2}{|c|}{$\begin{array}{c}\begin{array}{c}\text { Non- } \\
\text { obesity }\end{array} \\
(\mathrm{BMI}<30) \\
(\mathrm{N}=693 ; \\
70.5 \%)\end{array}$} & \multicolumn{2}{|c|}{$\begin{array}{c}\text { Obesity } \\
(\text { BMI } \geq 30) \\
(\mathrm{N}=290 \\
29.5 \%)\end{array}$} & \multirow[b]{2}{*}{$\chi^{2}$} & \multirow[b]{2}{*}{$\mathbf{P}$} & \multicolumn{2}{|c|}{$\begin{array}{c}\text { No } \\
\text { abdominal } \\
\text { obesity } \\
\text { (WHR < 0.85) } \\
(\mathrm{N}=559 ; \\
56.9 \%)\end{array}$} & \multicolumn{2}{|c|}{$\begin{array}{c}\text { Abdominal } \\
\text { obesity } \\
\text { (WHR } \geq 0.85) \\
(\mathrm{N}=424 ; \\
43.1 \%)\end{array}$} & \multirow[b]{2}{*}{$\chi^{2}$} & \multirow[b]{2}{*}{$p$} \\
\hline & $\mathrm{n}$ & $\%$ & $\mathrm{n}$ & $\%$ & $\mathrm{n}$ & $\%$ & & & $n$ & $\%$ & $\mathrm{n}$ & $\%$ & & \\
\hline \multicolumn{15}{|l|}{ Age (in years) } \\
\hline $35-44$ & 43 & 4.4 & 34 & 4.9 & 9 & 3.1 & 19.2 & $<.001$ & 34 & 6.1 & 9 & 2.1 & 52.0 & $<.001$ \\
\hline $45-54$ & 238 & 24.2 & 192 & 27.7 & 46 & 15.9 & & & 171 & 30.6 & 67 & 15.8 & & \\
\hline $55-64$ & 374 & 38.0 & 253 & 36.5 & 121 & 41.7 & & & 209 & 37.4 & 165 & 38.9 & & \\
\hline $65-74$ & 328 & 33.4 & 214 & 30.9 & 114 & 39.3 & & & 145 & 25.9 & 183 & 43.2 & & \\
\hline \multicolumn{15}{|l|}{ School education } \\
\hline High (grammar school [Gymnasium]) & 102 & 10.4 & 90 & 13.0 & 12 & 4.2 & 40.8 & $<.001$ & 77 & 13.8 & 25 & 5.9 & 38.1 & $<.001$ \\
\hline Medium (intermediate school [Realschule]) & 232 & 23.7 & 188 & 27.2 & 44 & 15.3 & & & 157 & 28.2 & 75 & 17.7 & & \\
\hline $\begin{array}{l}\text { Low (maximally secondary general school } \\
\text { [Hauptschule]) }\end{array}$ & 645 & 65.9 & 413 & 59.8 & 232 & 80.6 & & & 322 & 57.9 & 323 & 76.4 & & \\
\hline \multicolumn{15}{|l|}{ Family status } \\
\hline Living with partner & 712 & 72.5 & 501 & 72.4 & 211 & 72.8 & 0.0 & $<.908$ & 408 & 73.0 & 304 & 71.9 & 0.2 & .697 \\
\hline Not living with partner & 270 & 27.5 & 191 & 27.6 & 79 & 27.2 & & & 151 & 27.0 & 119 & 28.1 & & \\
\hline \multicolumn{15}{|l|}{ Health insurance } \\
\hline Private & 124 & 12.6 & 89 & 12.8 & 35 & 12.1 & 0.1 & .739 & 75 & 13.4 & 49 & 11.6 & 0.8 & .384 \\
\hline Statutory & 859 & 87.4 & 604 & 87.2 & 255 & 87.9 & & & 484 & 86.6 & 375 & 88.4 & & \\
\hline \multicolumn{15}{|l|}{ Place of residence } \\
\hline Rural & 542 & 55.1 & 381 & 55.0 & 161 & 55.5 & 0.0 & .877 & 315 & 56.4 & 227 & 53.5 & 0.8 & .380 \\
\hline Urban & 441 & 44.9 & 312 & 45.0 & 129 & 44.5 & & & 244 & 43.6 & 197 & 46.5 & & \\
\hline \multicolumn{15}{|l|}{ Depressed mood (DEEX-scale) } \\
\hline Yes & 392 & 40.0 & 272 & 39.4 & 120 & 41.7 & 0.5 & .503 & 224 & 40.1 & 168 & 40 & 0.0 & .982 \\
\hline No & 587 & 60.0 & 419 & 60.6 & 168 & 58.3 & & & 335 & 59.9 & 252 & 60 & & \\
\hline \multicolumn{15}{|l|}{ Diabetes mellitus } \\
\hline Yes & 82 & 8.3 & 37 & 5.3 & 45 & 15.5 & 27.7 & $<.001$ & 20 & 3.6 & 62 & 14.6 & 38.5 & $<.001$ \\
\hline No & 901 & 91.7 & 656 & 94.7 & 245 & 84.5 & & & 539 & 96.4 & 362 & 85.4 & & \\
\hline
\end{tabular}

with abdominal obesity $(15.5 \%$ vs. $5.3 \%$ and $14.6 \%$ vs. $3.6 \%$, respectively).

Table 2 shows the mean scores of the SF-12 in different subgroups. Physical HRQL decreases with age, lower school education, and is lower in participants with statutory health insurance. Additionally, it is significantly lower in participants with obesity, abdominal obesity, depressed mood, and diabetes. In contrast, mental HRQL is significantly lower only in participants with depressed mood, and marginally decreased in those not living with a partner and those with statutory health insurance.

\section{GLM}

In the four GLM, the hypotheses that the relations between obesity defined by BMI or WHR and HRQL are moderated by depressed mood and diabetes were scrutinized. Table 3 shows the results for obesity (BMI $\geq 30$ ) and Table 4 for abdominal obesity (WHR $\geq 0.85$ ) both for the physical sum score (left column) and the mental sum score (right column) of the SF-12, respectively. Regarding physical HRQL (SF-12 Physical Sum Score), for which results will be described first, all main effects (obesity, depression, and diabetes) as well as the three-way interaction are significant in the model with BMI (Table 3, left column). As the adjusted means for the main effects show, physical HRQL is lower in the presence of obesity, depressed mood, or diabetes, respectively (the pattern underlying the significant three-way interaction will be described in the next paragraph). In contrast, only the main effects of depressed mood and diabetes (and thus no interactions) are significant in the model with WHR (Table 4, left column). While here, the association of abdominal obesity with impaired physical HRQL in bivariate analysis is attenuated, adjusted means show that physical HRQL is impaired given either depressed mood or diabetes mellitus. This indicates that the association of abdominal 
Table 2 Physical and mental health-related quality of life (SF-12) in different sub-groups: unadjusted bivariate analysis

\begin{tabular}{|c|c|c|c|c|c|c|c|}
\hline \multirow[b]{2}{*}{ Source of variation } & & \multicolumn{3}{|c|}{ SF-12 Physical Sum Score } & \multicolumn{3}{|c|}{ SF-12 Mental Sum Score } \\
\hline & & Mean & $95 \%-\mathrm{Cl}$ & & Mean & $95 \%-\mathrm{Cl}$ & \\
\hline \multirow[t]{4}{*}{ Age (in years) } & $35-44$ & 48.7 & $45.9-51.5$ & $F_{(3,828)}=6.8, p \leq .001$ & 50.0 & $46.8-53.1$ & $F_{(3,828)}=1.5, p=.206$ \\
\hline & $45-54$ & 48.2 & $47.0-49.5$ & & 48.8 & $47.5-50.2$ & \\
\hline & $55-64$ & 46.2 & $45.2-47.2$ & & 56.1 & $49.0-51.2$ & \\
\hline & $65-74$ & 44.7 & $43.6-45.8$ & & 50.8 & $49.6-52.0$ & \\
\hline \multirow[t]{3}{*}{ Education } & High (grammar school) & 49.5 & $47.6-51.5$ & $F_{(2,825)}=5.6, p=.004$ & 49.4 & $47.2-51.6$ & $F_{(2,825)}=0.6, p=.557$ \\
\hline & Medium (intermediate school) & 46.2 & $44.9-47.4$ & & 49.5 & $48.2-50.9$ & \\
\hline & Low (max. secondary general school) & 46.0 & $45.2-46.7$ & & 50.3 & $49.4-51.2$ & \\
\hline \multirow[t]{2}{*}{ Family status } & Living with partner & 46.7 & $45.9-47.4$ & $F_{(1,829)}=2.6, p=.110$ & 50.4 & $49.6-51.2$ & $F_{(1,829)}=3.7, p=.056$ \\
\hline & Not living with partner & 45.5 & $44.3-46.7$ & & 48.9 & $47.5-50.2$ & \\
\hline \multirow[t]{2}{*}{ Health insurance } & Private & 48.1 & $46.3-49.8$ & $F_{(1,830)}=4.2, p=.041$ & 51.7 & 49.8-53.6 & $F_{(1,830)}=3.5, p=.061$ \\
\hline & Statutory & 46.1 & $45.4-46.8$ & & 49.7 & $49.0-50.5$ & \\
\hline \multirow[t]{2}{*}{ Place of residence } & Rural & 46.7 & $45.9-47.5$ & $F_{(1,830)}=1.5, p=.223$ & 49.6 & $48.7-50.5$ & $F_{(1,830)}=1.4, p=.232$ \\
\hline & Urban & 45.9 & $44.9-46.9$ & & 50.5 & $49.4-51.5$ & \\
\hline \multirow[t]{2}{*}{ Obesity (BMI $\geq 30$ ) } & Yes & 43.0 & $41.8-44.1$ & $F_{(1,830)}=47.3, p \leq .001$ & 50.2 & 48.9-51.5 & $F_{(1,830)}=0.1, p=.759$ \\
\hline & No & 47.7 & $47.0-48.5$ & & 50.0 & $49.1-50.7$ & \\
\hline \multirow{2}{*}{$\begin{array}{l}\text { Abdominal Obesity } \\
(\text { WHR } \geq 0.85)\end{array}$} & Yes & 45.4 & $44.4-46.4$ & $F_{(1,830)}=6.1, p=.014$ & 49.9 & $48.8-51.0$ & $F_{(1,830)}=0.1, p=.823$ \\
\hline & No & 47.0 & $46.2-47.9$ & & 50.1 & $49.2-51.0$ & \\
\hline \multirow{2}{*}{$\begin{array}{l}\text { Depressed mood } \\
\text { (DEEX-scale) }\end{array}$} & Yes & 42.5 & $41.6-43.4$ & $F_{(1,829)}=108.9, p \leq .001$ & 43.3 & $42.3-44.2$ & $F_{(1,829)}=341.8, p \leq .001$ \\
\hline & No & 49.0 & $48.2-49.7$ & & 54.5 & $53.7-55.2$ & \\
\hline \multirow[t]{2}{*}{ Diabetes mellitus } & Yes & 42.4 & $40.1-44.6$ & $F_{(1,830)}=13.1, p \leq .001$ & 48.5 & $46.0-51.0$ & $F_{(1,830)}=1.6, p=.213$ \\
\hline & No & 46.7 & $46.1-47.4$ & & 50.1 & $49.4-50.8$ & \\
\hline
\end{tabular}

obesity is mediated by one or both of depressed mood or diabetes mellitus as given co-morbidities.

Figure 1 shows the pattern underlying the three-way interaction in the model with obesity reported in Table 3 $(\mathrm{F}=4.1, \mathrm{p}=.044)$. Obesity is significantly associated with lower levels of physical HRQL only among non-diabetic women irrespective of depressed mood. Though among non-depressed diabetic women, the difference between obese vs. non-obese is numerically larger, it is statistically insignificant. Simultaneously, among those with both depressed mood and diabetes, the difference between obese and non-obese women is smallest among all comparisons.

Further exploration of the three-way interaction (not shown) revealed that while the two-way interaction of obesity with diabetes was significant both among those with and without depressed $\operatorname{mood}(\mathrm{F}=27.6$ and $\mathrm{F}=6.7$, both $\mathrm{p} \leq .01)$, the two-way interaction of obesity with depressed mood was significant only in the group without but not in that with diabetes $(\mathrm{F}=7.4, \mathrm{p}=.007$ vs. $\mathrm{F}$ $=0.7, \mathrm{p}=.405)$. In other words, in non-diabetic participants, the effect from BMI on physical HRQL is significantly amplified given depressed mood, i.e. the mean difference of -6.4 shown in Figure 1 is significantly higher than the mean difference of -2.5 .

Turning to mental HRQL, main effects of depressed mood and diabetes are seen, with the effect of depressed mood being considerably stronger (Table 3 and Table 4, right columns). In contrast, neither obesity nor abdominal obesity is significantly related to mental HRQL. While in both models the interaction between depressed mood and diabetes is significant, in the model with obesity the interaction with diabetes is significant as well. Figure 2 and Figure 3 show the underlying patterns. On one hand, obesity is associated with a marginally significant lower level of mental HRQL among women with diabetes, with no difference among those without diabetes (see Figure 2). On the other hand, depressed mood is associated with lower mental HRQL regardless of diabetes status, however more strongly so in the diabetes group (see Figure 3; estimates are from the BMImodel and equivalent to the WHR-model).

\section{Discussion}

Negative associations with physical but not mental HRQL were found for general and abdominal obesity in a community sample of postmenopausal women. Both obesity-indicators were associated with diabetes but not depressed mood, the latter being in line with cross-sectional studies from populations other than the US finding no associations between obesity and depression [28]. Moderating effects of depressed mood and diabetes on the relation between obesity and HRQL depended on 
Table 3 Physical and mental HRQL (SF-12) by obesity, diabetes mellitus, and depressed mood: GLM results ${ }^{\mathrm{a}}$

\begin{tabular}{|c|c|c|c|c|c|c|c|c|}
\hline \multirow[b]{2}{*}{ Source of variation } & & \multirow[b]{2}{*}{ Statistic } & \multicolumn{2}{|c|}{$\begin{array}{l}\text { SF-12 Physical } \\
\text { Sum Score }\end{array}$} & \multirow[b]{2}{*}{ Effect } & \multicolumn{2}{|c|}{$\begin{array}{l}\text { SF-12 Mental } \\
\text { Sum Score }\end{array}$} & \multirow[b]{2}{*}{ Effect } \\
\hline & & & Value & $95 \%-\mathrm{Cl}$ & & Value & $95 \%-\mathrm{Cl}$ & \\
\hline \multicolumn{9}{|l|}{ Obesity (BMI $\geq 30)$} \\
\hline & Yes & $\begin{array}{l}\text { Adjusted } \\
\text { mean }\end{array}$ & 42.0 & $40.5-43.6$ & $F_{(1,825)}=7.7, p=.006$ & 47.7 & $46.2-49.3$ & $F_{(1,825)}=0.3, p=.588$ \\
\hline & No & $\begin{array}{l}\text { Adjusted } \\
\text { mean }\end{array}$ & 45.2 & $43.6-46.8$ & & 48.3 & $46.7-49.9$ & \\
\hline \multicolumn{9}{|l|}{ Depressed mood (DEEX-scale) } \\
\hline & Yes & $\begin{array}{l}\text { Adjusted } \\
\text { mean }\end{array}$ & 39.7 & $38.0-41.5$ & $F_{(1,825)}=46.5, p<.001$ & 41.7 & $39.9-43.5$ & $F_{(1,825)}=122.4, p<.001$ \\
\hline & No & $\begin{array}{l}\text { Adjusted } \\
\text { mean }\end{array}$ & 47.5 & $46.0-48.9$ & & 54.4 & $52.9-55.8$ & \\
\hline \multicolumn{9}{|l|}{ Diabetes mellitus } \\
\hline & Yes & $\begin{array}{l}\text { Adjusted } \\
\text { mean }\end{array}$ & 42.2 & $40.0-44.3$ & $F_{(1,825)}=6.4, p=.012$ & 46.7 & $44.5-48.9$ & $F_{(1,825)}=5.3, p=.022$ \\
\hline & No & $\begin{array}{l}\text { Adjusted } \\
\text { mean }\end{array}$ & 45.0 & $44.4-45.7$ & & 49.4 & 48.7-50.1 & \\
\hline Obesity $\times$ Depressed Mood ${ }^{b}$ & & & & & $F_{(1,825)}=0.1, p=.775$ & & & $F_{(1,825)}=2.7, p=.104$ \\
\hline Obesity $\times$ Diabetes mellitus ${ }^{b}$ & & & & & $F_{(1,825)}=1.4, p=.236$ & & & $F_{(1,825)}=3.2, p=.074$ \\
\hline Depressed Mood $\times$ Diabetes mellitus ${ }^{b}$ & & & & & $F_{(1,825)}=0.6, p=.431$ & & & $F_{(1,825)}=3.7, p=.053$ \\
\hline $\begin{array}{l}\text { Obesity } \times \text { Depressed Mood } \times \text { Diabetes } \\
\text { mellitus } \mathrm{b}\end{array}$ & & & & & $F_{(1,825)}=4.1, p=.044$ & & & $F_{(1,825)}=0.6, p=.447$ \\
\hline
\end{tabular}

Notes: ${ }^{a}$ Adjusted for age, school education, family status, type of health insurance (statutory vs. private), and place of residence (urban vs. rural) ${ }^{\mathrm{b}}$ To simplify presentation, adjusted means for subgroups are not shown here (see below, interaction contrast analyses in figures 1 to 3 )

the HRQL-dimension. Depressed mood significantly reduced the score in physical HRQL, given no diabetes. In contrast, reduced mental HRQL associated with obesity was restricted to women with diabetes (independent of depressed mood). Finally, the effect of depressed mood in terms of reduced mental HRQL was found both in diabetic and non-diabetic women, but was stronger in the former group. Interactions between

Table 4 Physical and mental HRQL (SF-12) by abdominal obesity, diabetes mellitus, and depressed mood: GLM results ${ }^{\mathrm{a}}$

\begin{tabular}{|c|c|c|c|c|c|c|c|c|}
\hline \multirow[b]{2}{*}{ Source of variation } & & \multirow[b]{2}{*}{ Statistic } & \multicolumn{2}{|c|}{$\begin{array}{l}\text { SF-12 Physical } \\
\text { Sum Score }\end{array}$} & \multirow[b]{2}{*}{ Effect } & \multicolumn{2}{|c|}{$\begin{array}{l}\text { SF-12 Mental } \\
\text { Sum Score }\end{array}$} & \multirow[b]{2}{*}{ Effect } \\
\hline & & & Value & $95 \%-C$ & & Value & $95 \%-\mathrm{Cl}$ & \\
\hline \multicolumn{9}{|l|}{ Abdominal Obesity $(\mathrm{WHR} \geq 0.85)$} \\
\hline & Yes & $\begin{array}{l}\text { Adjusted } \\
\text { mean }\end{array}$ & 44.0 & $42.7-45.4$ & $F_{(1,825)}=0.0, p=.978$ & 47.7 & $46.4-49.1$ & $F_{(1,825)}=0.0, p=.990$ \\
\hline & No & $\begin{array}{l}\text { Adjusted } \\
\text { mean }\end{array}$ & 44.1 & $42.0-46.2$ & & 47.8 & $45.7-49.9$ & \\
\hline \multicolumn{9}{|l|}{ Depressed mood (DEEX-scale) } \\
\hline & Yes & $\begin{array}{l}\text { Adjusted } \\
\text { mean }\end{array}$ & 40.2 & $38.3-42.2$ & $F_{(1,825)}=35.9, p<.001$ & 40.9 & $38.9-42.8$ & $\begin{array}{l}F_{(1,825)}=118.0 \\
P<.001\end{array}$ \\
\hline & No & $\begin{array}{l}\text { Adjusted } \\
\text { mean }\end{array}$ & 47.9 & $46.3-49.5$ & & 54.6 & $53.0-56.2$ & \\
\hline \multicolumn{9}{|l|}{ Diabetes mellitus } \\
\hline & Yes & $\begin{array}{l}\text { Adjusted } \\
\text { mean }\end{array}$ & 42.2 & $39.7-44.6$ & $F_{(1,825)}=8.6, p=.003$ & 46.5 & $44.1-48.9$ & $F_{(1,825)}=3.8, p=.051$ \\
\hline & No & $\begin{array}{l}\text { Adjusted } \\
\text { mean }\end{array}$ & 46.0 & $45.0-46.6$ & & 49.0 & $48.4-49.6$ & \\
\hline Abdominal Obesity $\times$ Depressed Mood ${ }^{b}$ & & & & & $F_{(1,825)}=0.4, p=.834$ & & & $F_{(1,825)}=2.1, p=.144$ \\
\hline Abdominal Obesity $\times$ Diabetes mellitus ${ }^{b}$ & & & & & $F_{(1,825)}=0.3, p=.583$ & & & $F_{(1,825)}=0.2, p=.670$ \\
\hline Depressed Mood $\times$ Diabetes mellitus ${ }^{\mathrm{b}}$ & & & & & $F_{(1,825)}=1.2, p=.270$ & & & $F_{(1,825)}=5.2, p=.022$ \\
\hline $\begin{array}{l}\text { Abdominal Obesity } \times \text { Depressed Mood } \times \\
\text { Diabetes mellitus }{ }^{b}\end{array}$ & & & & & $F_{(1,825)}=0.6, p=.444$ & & & $F_{(1,825)}=2.4, p=.125$ \\
\hline
\end{tabular}

Notes: ${ }^{a}$ Adjusted for age, school education, family status, type of health insurance (statutory vs. private), and place of residence (urban vs. rural) ${ }^{b}$ To simplify presentation, adjusted means for subgroups are not shown here (see below, interaction contrast analyses in figures 1 to 3 ) 


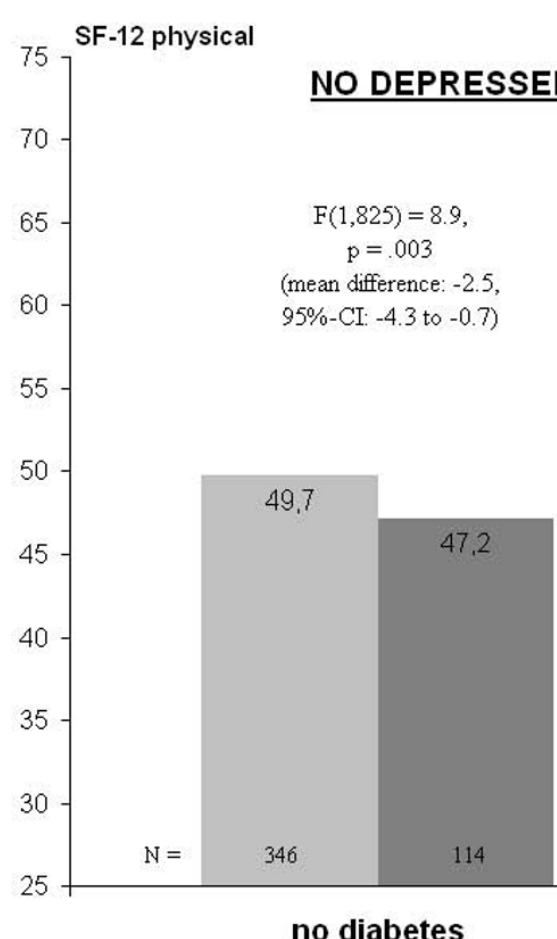

no diabetes
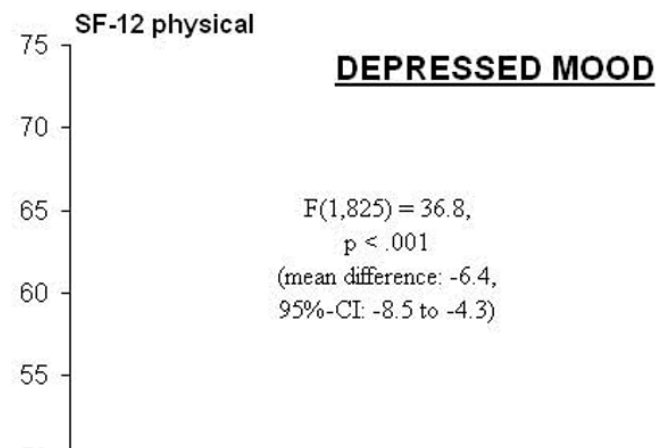

$$
p<.001
$$$$
\text { (25) }=36
$$

(mean difference: -6.4 ,

95\%-CI -8.5 to -4.3 )

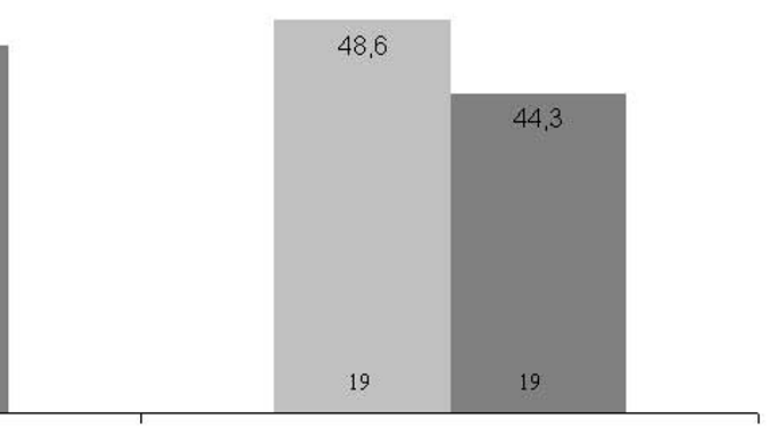

diabetes

$$
\begin{gathered}
p=.129 \\
\text { (mean difference: }-4,3 \text {, } \\
95 \%-C I:-9.7 \text { to } 1.0 \text { ) }
\end{gathered}
$$

non-obese

abese 
abdominal obesity and depression or diabetes were not observed.

These findings add observational evidence to the field of postmenopause, HRQL, and chronic medical conditions. In particular, that depressed mood as a mental illhealth state amplifies the negative impact of obesity on physical HRQL (given a healthy state in terms of no diabetes), while diabetes (as a physical disease) turned out to be a precondition for obesity-related impairments in mental HRQL, reflects complex interrelations. Also, it is intriguing that these patterns were found for general but not abdominal obesity, especially given the latter's significant role in the postmenopausal period [29]. Myint et al. [30] found that an increase in WHR, but not in BMI, was significantly associated with lower mental health. The present finding that an elevated BMI was associated with lower mental HRQL in diabetic participants may reflect that general obesity as a stressor may potentiate its unfavourable effect on mental HRQL when combined with a chronic condition.

Moreover, it is notable that the three-way interaction between obesity, depressed mood and diabetes regarding physical HRQL was driven more by the interaction of obesity with depressed mood than with diabetes. "Depressed mood" as defined by the DEEX-scale differs from other measures as it detects physical, non-stigmatizing symptoms, and resembles the concept of vital exhaustion [31]. This "general malaise" might prevent coping with the strains obesity imposes on physical HRQL. In contrast, diabetes may not only moderate, but also mediate the association between obesity and physical HRQL (similar to abdominal obesity), not least because the etiological role of (abdominal) obesity for

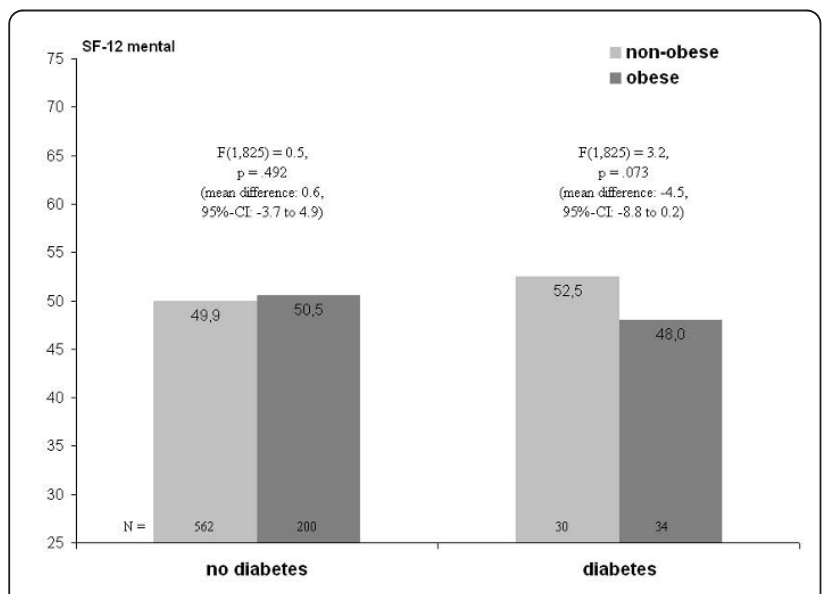

Figure 2 Two-way interaction of obesity and diabetes on mental HRQL (SF-12) $)^{\mathbf{a}, \mathbf{b}}$. a adjusted for age, education, family status, type of health insurance, and place of residence (urban vs. rural). ${ }^{b}$ F-values represent simple effects of obesity within groups defined by diabetes status.

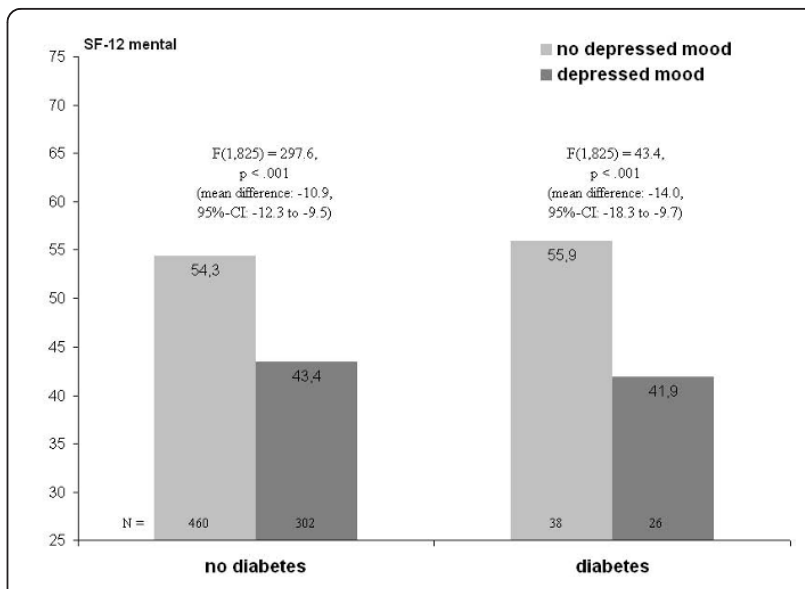

Figure 3 Two-way interaction of depressed mood and diabetes on mental HRQL (SF-12) ${ }^{\mathrm{a}, \mathrm{b}}$. a adjusted for age, education, family status, type of health insurance, and place of residence (urban vs. rural). ${ }^{b}$ F-values represent simple effects of depressed mood within groups defined by diabetes status.

diabetes is more clear-cut than for depressed mood $[13,14,20,21,28]$.

\section{Strengths and limitations}

A major strength of this study is the rigorous quality assurance applied during data collection [16], allowing to analyse a definite postmenopausal cohort with standardized, validated instruments. First, a limitation that derives from the observational, cross-sectional design is that reversed or bidirectional causality could not be ruled out. However, effects of chronic conditions on the relation between obesity and HRQL in postmenopausal women have hardly been studied, warranting report of the results.

Second, both the absolute sample size and observational approach implied an unbalanced design, of which subsample sizes are indicative. While generally, small subsamples tend to work against detecting significant differences (thus testing conservatively), more sophisticated analyses were unfeasible. Only two BMI- and WHR-groups along could be differentiated (e.g., there were only three normal weight women with diabetes). Similarly, different diabetes types could not be contrasted since only one of 82 had type 1 diabetes. Thus, results by and large reflect effects of type 2 diabetes. Also, factors such as other concomitant diseases, parity or sexual activity could not be considered. The choice of the DEEX-scale [23] in order to operationalise depressed mood was influenced by subsample sizes as well. This instrument has been shown to be useful to identify depressed mood in otherwise apparently healthy subjects in general populations. At the same time, unlike the Hospital Anxiety and Depression Scale it is not 
specifically designed for groups with physical diseases, and unlike the Patient Health Questionnaire-9 not directly based on the diagnostic criteria for major depressive disorders. However, in the present survey using these alternatives would have resulted in one-digit subsample sizes not suitable for analysis.

Third, the response rate (76\%), though comparing well to surveys with comparable participation time (in the present survey this was, on average, 175 minutes, which include all parts of the survey performed at one visit at the study centre, and possible breaks during this visit), may lead to selection biases, as healthier subjects are more likely to participate. Indeed, a non-responder survey in another KORA-study (S4) has revealed that responders tend to be healthier (e.g. in terms of lower diabetes rates; for details, see "Population and sampling"). Yet, this rather reduces ability to detect associations.

Fourth, HRQL-assessment by the SF-12 implies restrictions. Unlike the SF-36 it does not allow to analyse sub-dimensions of physical and mental HRQL (regarding its sum scores, however, it does compare well to the SF-36 in the context of obesity [32]]. Also, the SF-12 is a generic instrument, and might not reflect menopause-specific HRQL-dimensions as would e.g. the Menopause-specific Quality of Life Questionnaire [33] or the Menopause Rating Scale [34]. While the choice of the SF-12 related to the fact that the KORA-survey was not specifically designed to study menopausal issues, using a generic instrument may also have advantages in a study which scrutinizes different conditions (obesity, diabetes, and depressed mood) as joint determinants of postmenopausal HRQL. Thus, using a condition-specific instrument might have overlooked HRQLeffects of other conditions, respectively. Also, generic mental health-related quality of life has been shown to be affected by the greatest reductions after weight gain in a recent trial which included an obesity-specific measure (Impact of Weight on Quality of Life-Lite) [35].

Fifth, variances accounted for in GLM were 19\% for physical and 31\% for mental HRQL in the models with obesity, and $14 \%$ and $30 \%$ in those with abdominal obesity. Those explained by significant interactions did not exceed one percent. Also, cross-validating the complex interactions e.g. by partitioning was not possible, again due to sample size restrictions. In terms of clinical significance, however, the HRQL-impairments identified are important. Subgroups reporting poorest physical HRQL (obesity/depressed mood, and depressed mood/ diabetes) were worse off than those with either diabetes or any cancer (excluding skin carcinoma) in the SF-12 normative sample [18]. This also holds for the obesityassociated impairment in mental HRQL among women with diabetes.

\section{Conclusions}

This study provides observational evidence that depressed mood significantly elevates obesity-associated impairment in physical HRQL in postmenopausal women in absence of a chronic condition (here: diabetes), and that a significant reduction in mental HRQL is restricted to obese women with diabetes. These effects were not observed for abdominal obesity. By joint scrutiny of different chronic conditions, this study follows the call to consider clusters of symptoms, and mechanisms common to the clusters, in the context of developing a theoretical model of menopause, its symptoms, and quality of life [36]. It may contribute to tailoring interventions fostering HRQL in postmenopausal women. Regarding physical HRQL, women most in need may be those obese and feeling depressed. Regarding mental HRQL, obesity and diabetes as interacting factors seem worth of further scrutiny. In future studies, the underlying pathophysiological mechanisms should be investigated. Finally, lifestyle interventions should take into account low HRQL associated with concomitant depressed mood and diabetes, as it is a pre-treatment predictor of unsuccessful weight control [37].

\section{List of abbreviations}

BMI: body mass index; GLM: General Linear Models; HRQL: health-related quality of life; WHR: waist-to-hip ratio.

\section{Acknowledgements}

This research received no specific grant from any funding agency in the public, commercial, or not-for-profit sectors. This research uses data from the KORA Survey 2004-2005 (F3), a project conducted by the research platform KORA (Cooperative Health Research in the Region of Augsburg). KORA was initiated and financed by the Helmholtz Center Munich - German Research Center for Environmental Health (formerly: GSF - National Research Center for Environment and Health), Neuherberg, Germany, which is financed by the German Federal Ministry of Education and Research and the State of Bavaria.

\section{Author details}

${ }^{1}$ Hannover Medical School, Medical Psychology Unit (OE 5430), CarlNeuberg-Str. 1, 30625 Hannover, Germany. ${ }^{2}$ Helmholtz Center Munich German Research Center for Environmental Health, Institute of Health Economics and Health Care Management, Ingolstädter Landstr. 1, 85764 Neuherberg, Germany. ${ }^{3}$ Helmholtz Center Munich - German Research Center for Environmental Health, Institute of Epidemiology II, Ingolstädter Landstr. 1, 85764 Neuherberg, Germany.

\section{Authors' contributions}

$\mathrm{DAH}$ participated in the statistical analyses and the writing of the article. $\mathrm{RH}$ participated in the preparation and conduct of the study and the editing of the article. MEL participated in the conduct of the study and the editing of the article. KHL participated in the preparation and conduct of the study and the editing of the article. TVL participated in the preparation and conduct of the study, the statistical analyses and the writing of the article. All authors read and approved the final manuscript.

\section{Competing interests}

The authors declare that they have no competing interests.

Received: 13 May 2011 Accepted: 4 November 2011

Published: 4 November 2011 


\section{References}

1. National Institutes of Health: State-of-the-Science Conference Statement: Management of Menopause-Related Symptoms. Ann Intern Med 2005, 142:1003-1013.

2. Utian WH: Psychosocial and socioeconomic burden of vasomotor symptoms in menopause: a comprehensive review. Health Qual Life Outcomes 2005, 3:47.

3. Avis NE, Colvin A, Bromberger JT, Hess R, Matthews KA, Ory M, Schocken M: Change in health-related quality of life over the menopausal transition in a multiethnic cohort of middle-aged women: study of women's health across the nation. Menopause 2009, 16:860-869.

4. Williams RE, Levine KB, Kalilani L, Lewis J, Clark RV: Menopause-specific questionnaire assessment in US population-based study shows negative impact on health-related quality of life. Maturitas 2009, 62:153-159.

5. Timur S, Sahin NH: Effects of sleep disturbance on the quality of life of Turkish menopausal women: a population-based study. Maturitas 2009, 64:177-181.

6. Van Dole KB, Williams RE, Brown RS, Gaynes B, Devellis R, Funk MJ: Longitudinal association of vasomotor symptoms and psychosocial outcomes among postmenopausal women in the United States: a population-based study. Menopause 2010, 17:917-923.

7. Sanfélix-Genovés J, Hurtado I, Sanfélix-Gimeno G, Reig-Molla B, Peiró S: Impact of osteoporosis and vertebral fractures on quality of life: a population-based study in Valencia, Spain (The FRAVO Study). Health Qual Life Outcomes 2011, 9:20.

8. Schwarz S, Völzke H, Alte D, Schwahn C, Grabe HJ, Hoffmann W, John U, Dören M: Menopause and determinants of quality of life in women at midlife and beyond: the study of health in Pomerania (SHIP). Menopause 2007, 14:123-134.

9. Jones $G L$, Sutton A: Quality of life in obese postmenopausal women. Menopause Int 2008, 14:26-32.

10. von Lengerke T, Stehr M: [Are obese adults limited in their mental health-related quality of life? A systematic review of recent studies]. German (incl. English abstract) Adipositas 2011, 5:30-36.

11. Stunkard AJ, Faith MS, Allison KC: Depression and obesity. Biol Psychiatry 2003, 54:330-337.

12. Myers A, Rosen JC: Obesity stigmatization and coping: relation to mental health symptoms, body image, and self esteem. Int J Obes Relat Metab Disord 1999, 23:221-230.

13. Banegas JR, López-García E, Graciani A, Guallar-Castillón P, Gutierrez-Fisac JL, Alonso J, Rodríguez-Artalejo F: Relationship between obesity, hypertension and diabetes, and health-related quality of life among the elderly. Eur J Cardiovasc Prev Rehabil 2007, 14:456-462.

14. Ladwig K-H, Marten-Mittag B, Löwel H, Döring A, Wichmann H-E: Synergistic effects of depressed mood and obesity on long-term cardiovascular risks in 1510 obese men and women: results from the MONICA-KORA Augsburg Cohort Study 1984-1998. Int J Obes 2006, 30:1408-1414

15. Everson-Rose SA, Lewis TT, Karavolos K, Dugan SA, Wesley D, Powell LH: Depressive symptoms and increased visceral fat in middle-aged women. Psychosom Med 2009, 71:410-416.

16. Holle R, Happich M, Löwel H, Wichmann HE, MONICA/KORA Study Group: KORA - A Research Platform for Population Based Health Research. Gesundheitswesen 2005, 67:19-25.

17. Hoffmann W, Terschüren C, Holle R, Kamtsiuris P, Bergmann M, Kroke A, Sauer S, Stang A, Latza U: The problem of response in epidemiologic studies in Germany (part II) (in German). Gesundheitswesen 2004, 66:482-491.

18. Bullinger M, Kirchberger I: SF-36 Fragebogen zum Gesundheitszustand German. Göttingen: Hogrefe; 1998.

19. Qiao Q, Nyamdorj R: The optimal cutoff values and their performance of waist circumference and waist-to-hip ratio for diagnosing type II diabetes. Eur J Clin Nutr 2010, 64:23-29.

20. Vazquez G, Duval S, Jacobs DR, Silventoinen K: Comparison of body mass index, waist circumference, and waist/hip ratio in predicting incident diabetes: a meta-analysis. Epidemiol Rev 2007, 29:115-128.

21. Rivenes AC, Harvey SB, Mykletun A: The relationship between abdominal fat, obesity, and common mental disorders: results from the HUNT study. J Psychosom Res 2009, 66:269-275.

22. Singh D, Randall PK: Beauty is in the eye of the plastic surgeon: waist-hip ratio (WHR) and women's attractiveness. Pers Individ Dif 2007, 43:329-340.
23. Ladwig KH, Marten-Mittag B, Baumert J, Löwel H, Döring A, KORA investigators: Case-finding for depressive and exhausted mood in the general population: reliability and validity of a symptom-driven diagnostic scale. Results from the prospective MONICA/KORA Augsburg study. Ann Epidemiol 2004, 14:332-338.

24. Von Zerssen D, Koeller D-M: Die Beschwerden-Liste: Parallelformen B-L U. B-L', Ergänzungsbogen B-L* German. Weinheim: Beltz; 1976.

25. Nocon M, Keil T, Willich SN: Education, income, occupational status and health risk behaviour. J Public Health 2007, 15:401-405.

26. McClelland GH, Judd CM: Statistical difficulties of detecting interactions and moderator effects. Psychol Bull 1993, 114:376-390.

27. Page MC, Braver SL, MacKinnon DP: Levine's guide to SPSS for analysis of variance. 2 edition. New York: Lawrence Erlbaum; 2003.

28. Atlantis $\mathrm{E}$, Baker $\mathrm{M}$ : Obesity effects on depression: systematic review of epidemiological studies. Int J Obes 2008, 32:881-891.

29. Genazzani AR, Gambacciani M: Effect of climacteric transition and hormone replacement therapy on body weight and body fat distribution. Gynecol Endocrinol 2006, 22:145-150.

30. Mynt PK, Welch AA, Luben RN, Wainwright NWJ, Surtees PG, Bingham SA, Wareham NJ, Smith RD, Harvey IM, Khaw KT: Obesity indices and selfreported functional health in men and women in the EPIC-Norfolk. Obesity 2006, 14:884-893.

31. Appels A, Mulder P: Excess fatigue as a precursor of myocardial infarction. Eur Heart J 1988, 9:758-764

32. Wee CC, Davis RB, Hamel MB: Comparing the SF-12 and SF-36 health status questionnaires in patients with and without obesity. Health Qual Life Outcomes 2008, 6:11.

33. Hilditch JR, Lewis J, Peter A, van Maris B, Ross A, Franssen E, Guyatt GH, Norton PG, Dunn E: A menopause-specific quality of life questionnaire: development and psychometric properties. Maturitas 2008, 61:107-121.

34. Heinemann K, Ruebig A, Potthoff P, Schneider HP, Strelow F, Heinemann LA, Do MT: The Menopause Rating Scale (MRS) scale: a methodological review. Health Qual Life Outcomes 2004, 2:45.

35. Kolotkin RL, Norquist JM, Crosby RD, Suryawanshi S, Teixeira PJ, Heymsfield SB, Erondu N, Nguyen AM: One year health-related quality of life outcomes in weight loss trial participants: comparison of three measures. Health Qual Life Outcomes 2009, 7:53.

36. Wood NF: Menopause, symptoms, and quality of life: time for a theoretical framework. Menopause 2010, 17:892-893.

37. Teixeira PJ, Going SB, Sardinha LB, Lohman TG: A review of psychosocial pre-treatment predictors of weight control. Obes Rev 2005, 6:43-65.

doi:10.1186/1477-7525-9-97

Cite this article as: Heidelberg et al:: Do diabetes and depressed mood affect associations between obesity and quality of life in postmenopause? Results of the KORA-F3 Augsburg population study. Health and Quality of Life Outcomes 2011 9:97.

\section{Submit your next manuscript to BioMed Central and take full advantage of:}

- Convenient online submission

- Thorough peer review

- No space constraints or color figure charges

- Immediate publication on acceptance

- Inclusion in PubMed, CAS, Scopus and Google Scholar

- Research which is freely available for redistribution

Submit your manuscript at www.biomedcentral.com/submit
C Biomed Central 